Check for updates

Cite this: RSC Adv., 2017, 7, 51814

Received 10th September 2017

Accepted 1st November 2017

DOI: $10.1039 / c 7 r a 10067 a$

rsc.li/rsc-advances

\section{Biodiesel production from soybean oils by a novel nano-magnetic solid base catalyst $\left(\mathrm{K} / \mathrm{ZrO}_{2} / \gamma-\right.$ $\left.\mathrm{Fe}_{2} \mathrm{O}_{3}\right)$}

\author{
Kang Liu, ${ }^{\text {ab }}$ Rui Wang (D) *a and Meiqing Yu ${ }^{\text {ab }}$
}

Biodiesel is emerging as a green alternative source to fossil fuels due to its clean and renewable advantages. In this study, a nano-solid base catalyst $\left(\mathrm{K} / \mathrm{ZrO}_{2} / \gamma-\mathrm{Fe}_{2} \mathrm{O}_{3}\right)$ with weak magnetism was successfully synthesized and investigated for transesterification of soybean oil to produce biodiesel. The obtained catalyst was fully characterized by X-ray diffraction (XRD), Brunauer-Emmett-Teller (BET), transmission electron microscopy (TEM), vibrating sample magnetometer (VSM), thermogravimetry/differential scanning calorimetry device (TG/DSC), and scanning electron microscopy-energy dispersive X-ray (SEMEDX) analysis. Results showed that the nano-magnetic catalyst had granular nano-structures with particle sizes of 15-25 nm. The optimum conditions for transesterification were shown to be as follows: catalyst added amount of $5 \mathrm{wt} \%$; methanol/oil molar ratio of $10: 1$; reaction time of $3.0 \mathrm{~h}$, and reaction temperature of $65{ }^{\circ} \mathrm{C}$, and the yield of biodiesel could reach above $93.6 \mathrm{wt} \%$. The reusability of the magnetic catalyst demonstrated that the magnetic catalyst was ferromagnetic and still maintained high catalytic activity after six times' reuse. The formed core-shell was hard to separate even after stirring in liquid phase reactions, which was favorable for use in biodiesel production. The developed nanomagnetic catalyst shows a potential application for biodiesel production in a green manner.

\section{Introduction}

The growing demand for energy around the world has aroused great attention to the exploration of new fuels and energy. ${ }^{\mathbf{1 , 2}}$ Nowadays, biodiesel is emerging as an alternative diesel fuel for fossil fuels., ${ }^{3,4}$ Biodiesel, which can be synthesized by the transesterification of waste oils or animal fats with a shortchain alcohol, is considered a new renewable energy source. ${ }^{5,6}$ In previous studies, biodiesel has been confirmed to be better than diesel fuel with a series of advantages, such as sulfur content, aromatic content, and cetane number., ${ }^{7,8}$ Besides, compared to normal diesel, biodiesel is non-toxic and biodegradable. ${ }^{9}$ Thus, the emission of greenhouse gases can be greatly reduced..$^{\mathbf{1 0 , 1 1}}$

Generally, transesterification reactions can be catalyzed by using a suitable catalyst, such as an inorganic base, inorganic acid or enzyme with high reactivity. ${ }^{12,13}$ Though homogeneous base catalysts have been confirmed to provide much faster reaction rates than heterogeneous catalysts, they also present many defects in biodiesel production, such as damaging the equipment, difficulty of product separation, and reclamation difficulty. ${ }^{\mathbf{1 4 1 5}}$ To overcome these disadvantages of

${ }^{a}$ Shenzhen Research Institute of Shandong University, Shenzhen 518057, Guangdong, China.E-mail: wangrui@sdu.edu.cn

${ }^{b}$ School of Environmental Science \& Engineering, Shandong University, Jinan 250199, China homogeneous catalysts, nano-magnetic catalysts were considered as ideal replacements for catalytic reactions. ${ }^{16,17}$

The previous studies indicated that nano-magnetic catalysts with high ratio surface area and high surface energy may be a better choice for biodiesel production. ${ }^{18-20}$ Meanwhile, compared with the conventional heterogeneous catalysts, the nano-magnetic catalysts would be easily separated and reused by external magnetic field after the transesterification reaction. ${ }^{21,22}$ Zhang et al. $^{23}$ developed a magnetic catalyst $\left(\mathrm{Na}_{2} \mathrm{SiO}_{3} @ \mathrm{Fe}_{3} \mathrm{O}_{4} / \mathrm{C}\right)$ for biodiesel production from oils under ultrasonic (US) irradiation. The magnetic catalyst could be easily magnetically separated for five cycles with $94.9 \mathrm{wt} \%$ recovery rate. Xue et $a{ }^{24}{ }^{24}$ prepared a novel magnetic catalyst $\left(\mathrm{CaFe}_{2} \mathrm{O}_{4}-\mathrm{Ca}_{2} \mathrm{Fe}_{2} \mathrm{O}_{5}\right)$ by co-precipitation and calcination. The catalysts could be recycled three times with above $78.2 \mathrm{wt} \%$ biodiesel yield. These reports indicated that the magnetic solid base catalyst is an efficient and green catalyst for the industrial production of biodiesel. Therefore, to develop the new magnetic catalyst not only provides a new choice for the biodiesel production, but also provides a new technology for the rapid recovery and separation of the catalysts.

Herein, a magnetic catalyst with nano-structure, named as $\mathrm{K} / \mathrm{ZrO}_{2} / \gamma-\mathrm{Fe}_{2} \mathrm{O}_{3}$ was successfully prepared by sol-gel method. The obtained magnetic catalyst was applied as a catalyst in the transesterification reaction with methanol as reaction reagent. The structure and properties of the magnetic catalyst was fully characterized by X-ray diffraction (XRD), 
Brunauer-Emmette-Teller (BET), transmission electron microscope (TEM), vibrating sample magnetometer (VSM), thermogravimetry/differential scanning calorimetry device (TG/ DSC). The preparation conditions and the optimal parameters of transesterification were also studied. The results demonstrated that the magnetic particles were fully encapsulated in the $\mathrm{ZrO}_{2}$ particles, which was beneficial to the separation and recycle. The conjunction of $\mathrm{ZrO}_{2}$ and $\mathrm{Fe}_{2} \mathrm{O}_{3}$ not only presented strong psychic magnetism of catalysts, but also significantly prevented the magnetic particles loss.

\section{Materials and methods}

\subsection{Materials and reagents}

Soybean oil was purchased from supermarket (Jinan, China). Ammonia solution (25 wt\%), methanol, potassium hydroxide $(\mathrm{KOH})$, zirconium oxychloride $\left(\mathrm{ZrOCl}_{2} \cdot 8 \mathrm{H}_{2} \mathrm{O}\right)$, ferrous chloride tetrahydrate $\left(\mathrm{FeCl}_{2} \cdot 4 \mathrm{H}_{2} \mathrm{O}\right)$ and six hydrated ferric chloride $\left(\mathrm{FeCl}_{3} \cdot 6 \mathrm{H}_{2} \mathrm{O}\right)$ were purchased from Sinopharm (Shanghai, China). Methyl linoleate, methyl palmitate, methyl oleate, methyl stearate, methyl linolenate, and methyl heptadecanoate, used as standard materials, were purchased from J\&K (Beijing, China). Deionized water was used for preparation and dilution of chemical solutions.

\subsection{Preparation of nano-magnetic catalyst}

The $\mathrm{FeCl}_{2} \cdot 4 \mathrm{H}_{2} \mathrm{O}$ and $\mathrm{FeCl}_{3} \cdot 6 \mathrm{H}_{2} \mathrm{O}$ with a mole proportion of $1: 2$ were synchronously dissolved in the deionized water. $\mathrm{ZrOCl}_{2}$ $\cdot 8 \mathrm{H}_{2} \mathrm{O}$ were then dropped into mixed solution with constantly stirring. Ammonia of $25 \mathrm{wt} \%$ was then added into the above solution in a water bath with the heating temperate of $25{ }^{\circ} \mathrm{C}$. The gel-sol $\left(\mathrm{Zr}(\mathrm{OH})_{4}-\mathrm{Fe}(\mathrm{OH})_{3}\right)$ produced by the chemical reaction can be obtained after filtration, separation and washing treatment. After drying the free water at $105{ }^{\circ} \mathrm{C}$, the gel-sol $\mathrm{KOH} /\left(\mathrm{Zr}(\mathrm{OH})_{4}-\mathrm{Fe}(\mathrm{OH})_{3}\right)$ was prepared by impregnation of the zirconium hydroxide with an aqueous solution of $\mathrm{KOH}$. The impregnated precursor was calcined in a muffle furnace with different temperature. Finally, the obtained solid powder was viewed as nano-magnetic catalyst solid base catalyst $\mathrm{K} / \mathrm{ZrO}_{2} / \gamma$ $\mathrm{Fe}_{2} \mathrm{O}_{3}$ (Fig. 1).

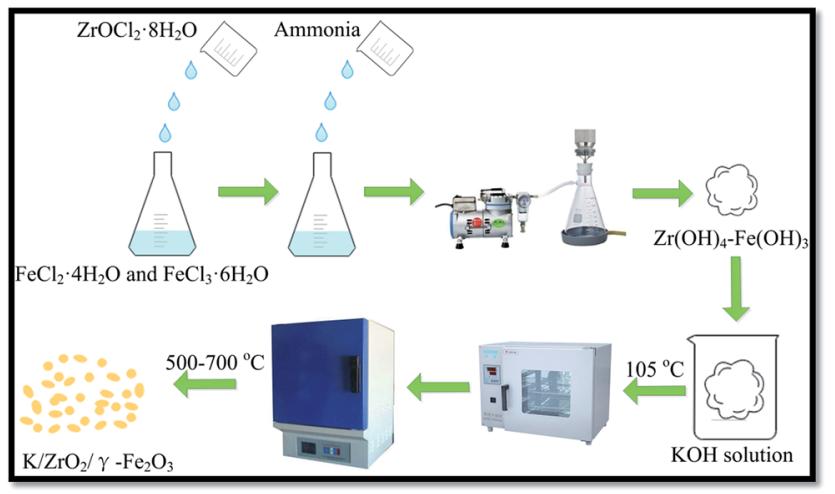

Fig. 1 Synthesis diagram of the nano-magnetic catalyst $\mathrm{K} / \mathrm{ZrO}_{2} / \gamma$ $\mathrm{Fe}_{2} \mathrm{O}_{3}$.

\subsection{Transesterification of soybean oil with methanol}

At the beginning of the experiment, a certain proportion of soybean oil, methanol, and the obtained nano-magnetic catalyst $\mathrm{K} / \mathrm{ZrO}_{2} / \gamma-\mathrm{Fe}_{2} \mathrm{O}_{3}$ were together added into a $100 \mathrm{ml}$ neck flask with vigorous stirring. The water bath temperature for the transesterification reaction was controlled between 50 and $70{ }^{\circ} \mathrm{C}$. After transesterification reaction in a set reaction time, the nano-magnetic catalyst could be recovered by a permanent magnet. The reaction sample after transesterification reaction became biphasic. After split-phase, the upper phase containing the biodiesel was revolved to remove the superfluous methanol. And the purified sample was directly analyzed the yield of biodiesel by using a gas chromatography.

\subsection{Analysis and characterization}

To detect the biodiesel yield, methyl heptadecanoate was employed as an internal standard. And normal hexane was used as diluted solvent. The yield of biodiesel samples after transesterification reaction was analyzed by a SP-6800 gas chromatograph equipped with a flame ionization detector and a capillary column AT. FFAP $(30 \mathrm{~m} \times \Phi 0.32 \mathrm{~mm} \times 0.33 \mu \mathrm{m})$. The yield of biodiesel was calculated by the following equation:

$$
\text { yield }_{\text {FAME }}=\frac{\sum f_{\text {ester }} A_{\text {ester }}}{A_{\text {internal }}} \times \frac{m_{\text {internal }}}{m_{\text {esters }}} \times 100 \%
$$

following the above formula, $A_{\text {ester }}$ is the peak area of methyl esters, $A_{\text {internal }}$ is the peak area of internal standard, $m_{\text {internal }}$ is the mass of internal standard, $m_{\text {esters }}$ is the mass of fatty acid methyl esters and $f_{\text {ester }}$ is the correction factor of fatty acid methyl esters.

The specific surface area was calculated by BrunauerEmmett-Teller (BET) method from the linear part of the nitrogen adsorption isotherms. Total pore volume $\left(V_{\text {tot }}\right)$ was given at $p / p^{0}=0.998$. The mesopores volume and pore size distribution were calculated according to the Barrett-JoynerHalenda (BJH) method from the desorption branch of isotherm. The nitrogen adsorption and desorption isotherms were measured at $-196{ }^{\circ} \mathrm{C}$ using NDVA2000e analytical system made by Qunta chrome Corporation (USA). Before the measurement all samples were degassed at $120{ }^{\circ} \mathrm{C}$ for $12 \mathrm{~h}$ under reduced pressure ( $<1$ torr) prior to sorption measurements. X-ray diffraction (XRD) patterns of selected samples were recorded by the reflection scan with nickel-filtered $\mathrm{Cu}$ Ka radiation (D8, Bruker-AXS, Germany). The X-ray generator was run at $40 \mathrm{kV}$ and $60 \mathrm{~mA}$. All the XRD measurements were performed at $2 \theta$ values between 10 and $80^{\circ}$. Thermal decomposition was evaluated by thermogravimetric analysis (TGA) and differential scanning calorimetry (DSC) was carried out on a SDT Q600 Universal V4.1D TA instrument operating under a flow of $\mathrm{N}_{2}$ at a $10{ }^{\circ} \mathrm{C} \mathrm{min}^{-1}$ heating rate up to $700{ }^{\circ} \mathrm{C}$. Magnetization curves were measured on a vibrating sample magnetometer (LDJ9500, VSM, the United States) with a magnetic field of 10000 Oe. Metal contents of the biodiesel samples were determined by inductively coupled plasma-optical emission spectrometer (ICPOES, OPTIMA 8300, PerkinElmer, USA) and inductively coupled plasma mass spectrometry (ICP-MS, NexION 350, PerkinElmer, 
USA), respectively, after the $\mathrm{HNO}_{3}-\mathrm{HCl}-\mathrm{HF}$ digestion. The morphological property of the catalyst was examined by a scanning electron microscope with energy dispersive X-ray analysis (SEM-EDX, Hitachi S-3000N, Japan).

\section{Results and discussion}

\subsection{Effect of the preparation conditions on biodiesel yield}

Various preparation conditions, such as $\mathrm{KOH}$ loading amount and calcination temperature of magnetic catalyst was evaluated in the transesterification of soybean oil with methanol. A series of $\mathrm{K} / \mathrm{ZrO}_{2} / \gamma-\mathrm{Fe}_{2} \mathrm{O}_{3}$ catalysts with $\mathrm{KOH}$ loaded ranging from 10 to $35 \mathrm{wt} \%$ were prepared and calcined at $600{ }^{\circ} \mathrm{C}$ in air for $4 \mathrm{~h}$. The biodiesel yield was improved from $41.4 \mathrm{wt} \%$ to $90.4 \mathrm{wt} \%$ when the $\mathrm{KOH}$ loading increased from $10 \mathrm{wt} \%$ to $30 \mathrm{wt} \%$ (Fig. 2a). It shows that the increasing of $\mathrm{KOH}$ loading amount was favor for the increase of the active sites of catalyst surface. When the $\mathrm{KOH}$ loading amount was beyond $30 \mathrm{wt} \%$, the activity of catalyst was decreased significantly. Therefore, the optimum loading amount of $\mathrm{KOH}$ was $30 \mathrm{wt} \%$. In the preparation process of catalyst, calcination treatment of catalyst at high temperature was favorable for the interaction between support and active ingredient, which generated new active sites for the catalyst. With the increase of calcination temperature, the biodiesel yield significantly increased as the calcinations temperature rose from $500{ }^{\circ} \mathrm{C}$ to $600{ }^{\circ} \mathrm{C}$. And the yield of biodiesel reached the highest 90.4 wt\% (Fig. 2b). However, the yield decreased slightly after the temperature exceeded $600{ }^{\circ} \mathrm{C}$. Therefore, the best calcination temperature for catalyst preparation was $600{ }^{\circ} \mathrm{C}$.

Previous research had documented that, $\mathrm{ZrO}_{2}$ can be regarded as a best support for the rich vacancies on the surface which the cations were easy to be inserted in. ${ }^{25-27}$ The crystallization of $\mathrm{Zr}(\mathrm{OH})_{4}$ created a considerable number of vacancies on the surface of $\mathrm{ZrO}_{2}$ during heating treatment. The molten $\mathrm{KOH}$ released $\mathrm{K}^{+}$into the vacancies and the $\mathrm{K}^{+}$possibly occupy the position of octa-coordinated $\mathrm{Zr}^{4+}$ to form $\mathrm{K}-\mathrm{O}-\mathrm{Zr}$ solid solution, forming strong basic and super basic sites. The main contribution to the transesterification is the new-formed active sites

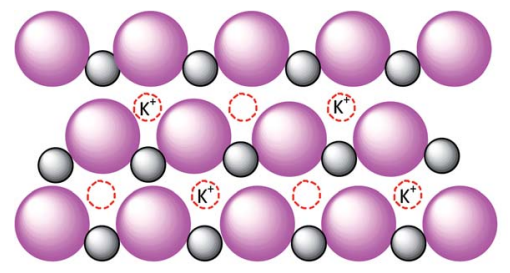

Lattice $\mathrm{O}^{2-} \mathrm{Or} \mathrm{Zr}^{4+}$ Vacant sites

Fig. 3 Diagram of the major mechanism of active sites for transesterification.

of $\mathrm{KO}_{x}$ species and $\mathrm{K}-\mathrm{O}-\mathrm{Zr}$ groups (Fig. 3). Thus, a high temperature was favorable for the production of oxygen vacancies. But the high temperature also caused the agglomeration of catalyst and the decrease of specific surface area, which directly led to an inferior catalytic activity.

\subsection{Catalyst characterization}

3.2.1. BET. Table 1 showed that the catalyst possessed a surface area of $20.08 \mathrm{~m}^{2} \mathrm{~g}^{-1}$, pore volume of $0.051 \mathrm{~m}^{3} \mathrm{~g}^{-1}$ and an average pore diameter of $10.146 \mathrm{~nm}$. The BET isotherm of the catalyst was of type IV. The $\mathrm{H}_{3}$ hysteresis loop at relative pressure 0.6-0.998 indicated that the magnetic catalyst possessed the characteristics of mesoporous materials (Fig. 4)

3.2.2. SEM-EDX and TEM. It can be seen from Fig. 5 that the zirconia particles exhibited tetragonal shape. These zirconia particles were distributed homogeneously and evenly. According to speculation, iron oxide nanoparticles were wrapped by the zirconia particles. The coated structure of nano-magnetic catalyst was characterized by TEM analysis. Fig. 6a and b shows that the black $\mathrm{Fe}_{2} \mathrm{O}_{3}$ was coated by $\mathrm{Zr}(\mathrm{OH})_{4}$ with the amorphous form in precursor. The typical coated structure of $\mathrm{K} / \mathrm{ZrO}_{2} / \gamma-\mathrm{Fe}_{2} \mathrm{O}_{3}$ can be clearly observed, indicating the successful coating of $\mathrm{ZrO}_{2}$ on $\mathrm{Fe}_{2} \mathrm{O}_{3}$ by sol-gel method (Fig. 6c). The diameter of $\mathrm{K} / \mathrm{ZrO}_{2} / \gamma-\mathrm{Fe}_{2} \mathrm{O}_{3}$ was approximately $20 \mathrm{~nm}$.
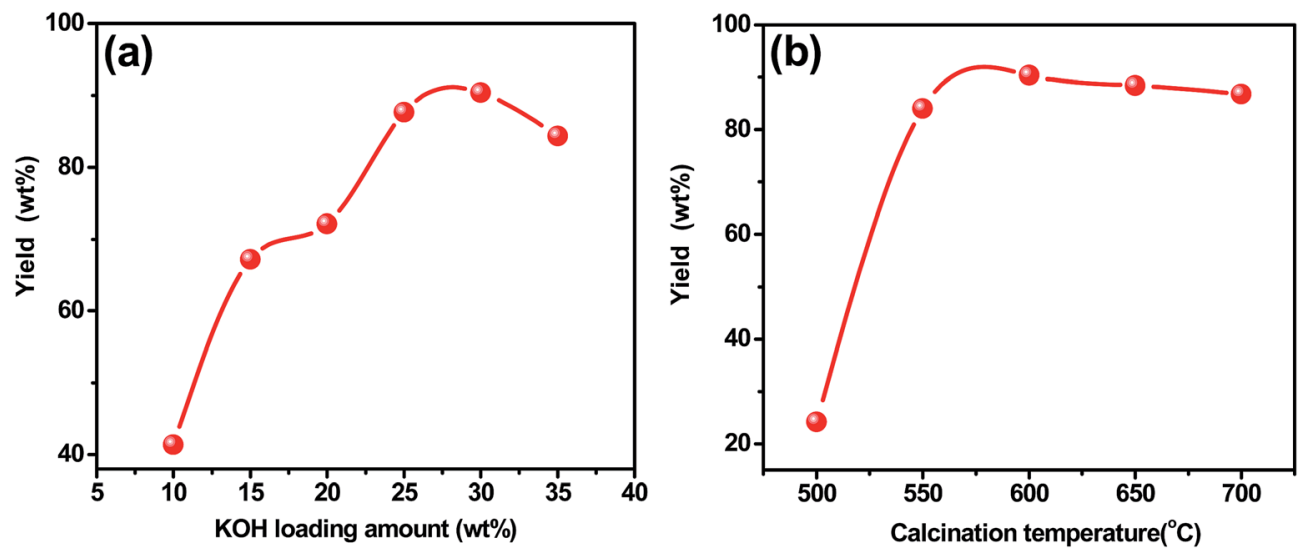

Fig. 2 Effects of (a) $\mathrm{KOH}$ loading amount; (b) calcination temperature (transesterification conditions: reaction temperature: $65^{\circ} \mathrm{C}$; methanol/oil: 8 : 1; catalyst amount: $4 \mathrm{wt} \%$; reaction time: $3 \mathrm{~h}$ ). 
Table 1 Physicochemical properties of magnetic catalyst ${ }^{a}$

\begin{tabular}{lllll}
\hline Sample & $\begin{array}{l}\text { Molar ratio } \\
\text { Fe }: \text { Zr }\end{array}$ & $S_{\text {BET }}\left(\mathrm{m}^{2} \mathrm{~g}^{-1}\right)$ & $D_{\text {av }}(\mathrm{nm})$ & $V_{\text {total }}\left(\mathrm{cm}^{3} \mathrm{~g}^{-1}\right)$ \\
\hline ZFK & $1: 15$ & 20.08 & 10.146 & 0.051
\end{tabular}

${ }^{a} S_{\mathrm{BET}}, D_{\mathrm{av}}, V_{\mathrm{total}}$, and $V_{\mathrm{mic}}$ denote BET surface area, total pore volume, micro porous total pore volume and average pore diameter, respectively. ZFK represents the precursor with $30 \mathrm{wt} \% \mathrm{KOH}$ loading amount after calcining at $600{ }^{\circ} \mathrm{C}$ for $4 \mathrm{~h}$.

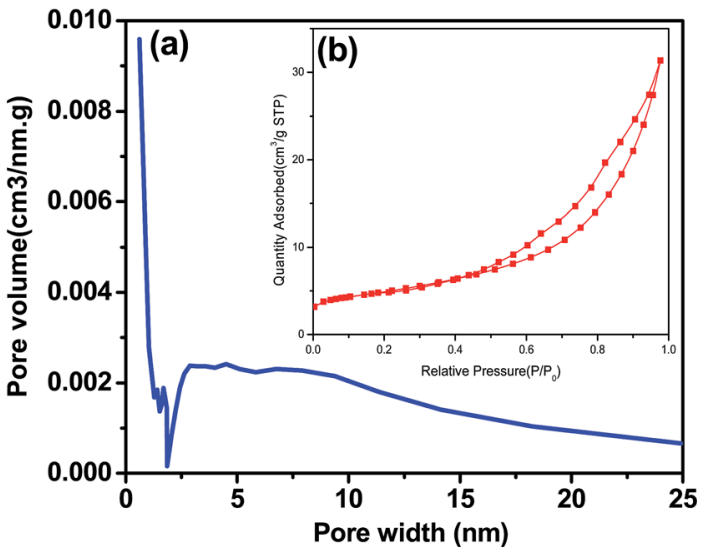

Fig. 4 (a) Pore size distribution curves. (b) Nitrogen adsorptiondesorption isotherm.

3.2.3. XRD. Fig. 7 demonstrates the XRD patterns of precursor with different calcination temperature. The XRD pattern in the top right-hand corner presented that the precursor appeared amorphous diffraction peak at $10^{\circ}-30^{\circ}$. The tetragonal form $\left(2 \theta=30.28^{\circ}, 50.48^{\circ}\right.$, and $\left.60.28^{\circ}\right)$ appeared after calculation at $600{ }^{\circ} \mathrm{C}$, indicating that the $\mathrm{Zr}(\mathrm{OH})_{4}$ was converted to tetragonal crystal $\left(\mathrm{t}-\mathrm{ZrO}_{2}\right)$. Subsequently, the monoclinic baddeleyite phase $\left(2 \theta=28.2^{\circ}\right)$ appeared after calculation at $700{ }^{\circ} \mathrm{C}$, indicating that partial tetragonal crystal in $\mathrm{ZrO}_{2}$ was converted to monoclinic baddeleyite $\left(\mathrm{m}-\mathrm{ZrO}_{2}\right)$.
3.2.4. TG-DSC. The TG-DSC curve presented the weight loss of precursor during heating treatment (Fig. 8). The TG peak around $100{ }^{\circ} \mathrm{C}$ was assigned to the loss of physical adsorbed $\mathrm{H}_{2} \mathrm{O}$, while the other one around $100-500{ }^{\circ} \mathrm{C}$ could be attributed to the removal of hydroxyl groups in $\mathrm{Zr}(\mathrm{OH})_{4}$. The TG-DSC curve of precursor exhibited an exothermic weight loss around $613.23{ }^{\circ} \mathrm{C}$, indicating the decomposition of $\mathrm{KOH}$. The results suggested that the best calcination temperature for catalyst preparation was $600{ }^{\circ} \mathrm{C}$, which was in accordance with the result in Section 3.1.

3.2.5. VSM. Fig. 9 demonstrates that all the magnetic catalyst samples, including the precursor, recovery catalyst and the catalysts calcined at different temperature, had the ferromagnetic behavior characteristic and show superparamagnetism (all curves go through the zero point). The saturation magnetization of precursor was the highest $23.3 \mathrm{emu}^{-1}$ due to the existence of $\mathrm{Fe}_{3} \mathrm{O}_{4}$. The magnetization of catalyst calcined at $500{ }^{\circ} \mathrm{C}$ (9.91 emu g $^{-1}$ ) was weaker than the precursor, because the $\mathrm{Fe}_{3} \mathrm{O}_{4}$ was oxidized to $\gamma-\mathrm{Fe}_{2} \mathrm{O}_{3}$ during the calcination process which led to the decrease of magnetization. ${ }^{28}$ But when the catalyst was calcined at $600{ }^{\circ} \mathrm{C}$, the saturation magnetization $\left(15.4 \mathrm{emu} \mathrm{g}^{-1}\right)$ of magnetic catalyst increased markedly. Combined with the result of XRD test, it could be concluded that the molecular layer of zirconia crystal tended to grow thin with the removal of hydroxyl groups on the surface of $\mathrm{Zr}(\mathrm{OH})_{4}$, resulting in the increase of mass ratio of $\gamma-\mathrm{Fe}_{2} \mathrm{O}_{3}$. Part of iron oxide nanoparticles, originally coated by $\mathrm{Zr}(\mathrm{OH})_{4}$, exposed in the
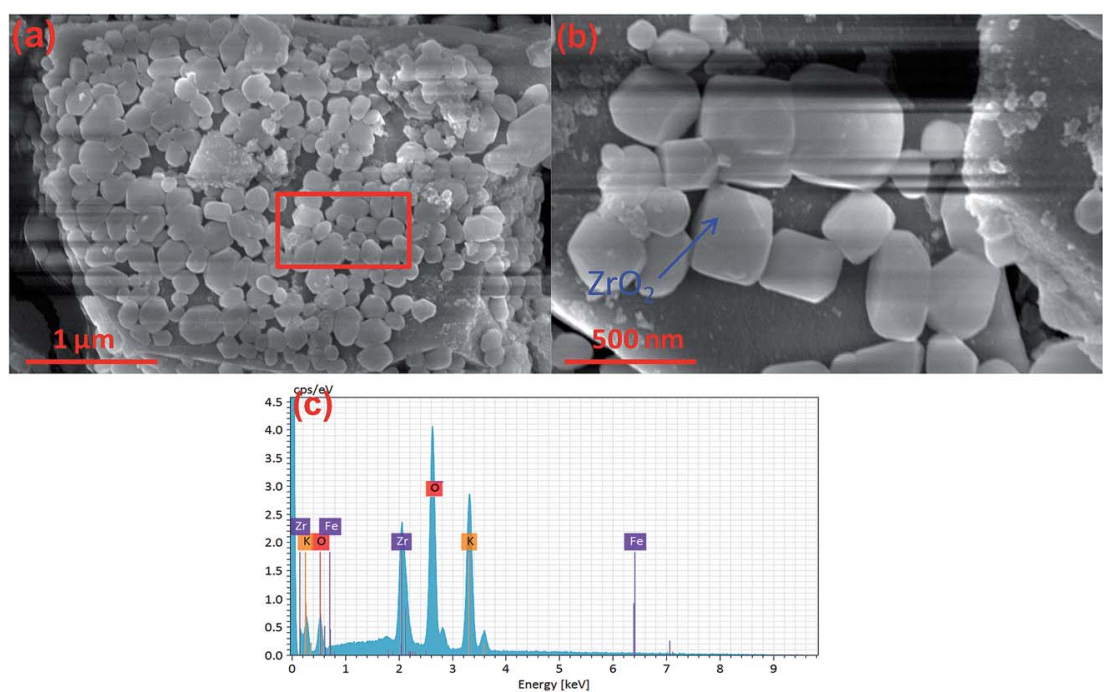

Fig. 5 (a, b) SEM images and (c) EDX of the nano-magnetic catalyst $\mathrm{K} / \mathrm{ZrO} \mathrm{O}_{2} / \gamma-\mathrm{Fe}_{2} \mathrm{O}_{3}$ 

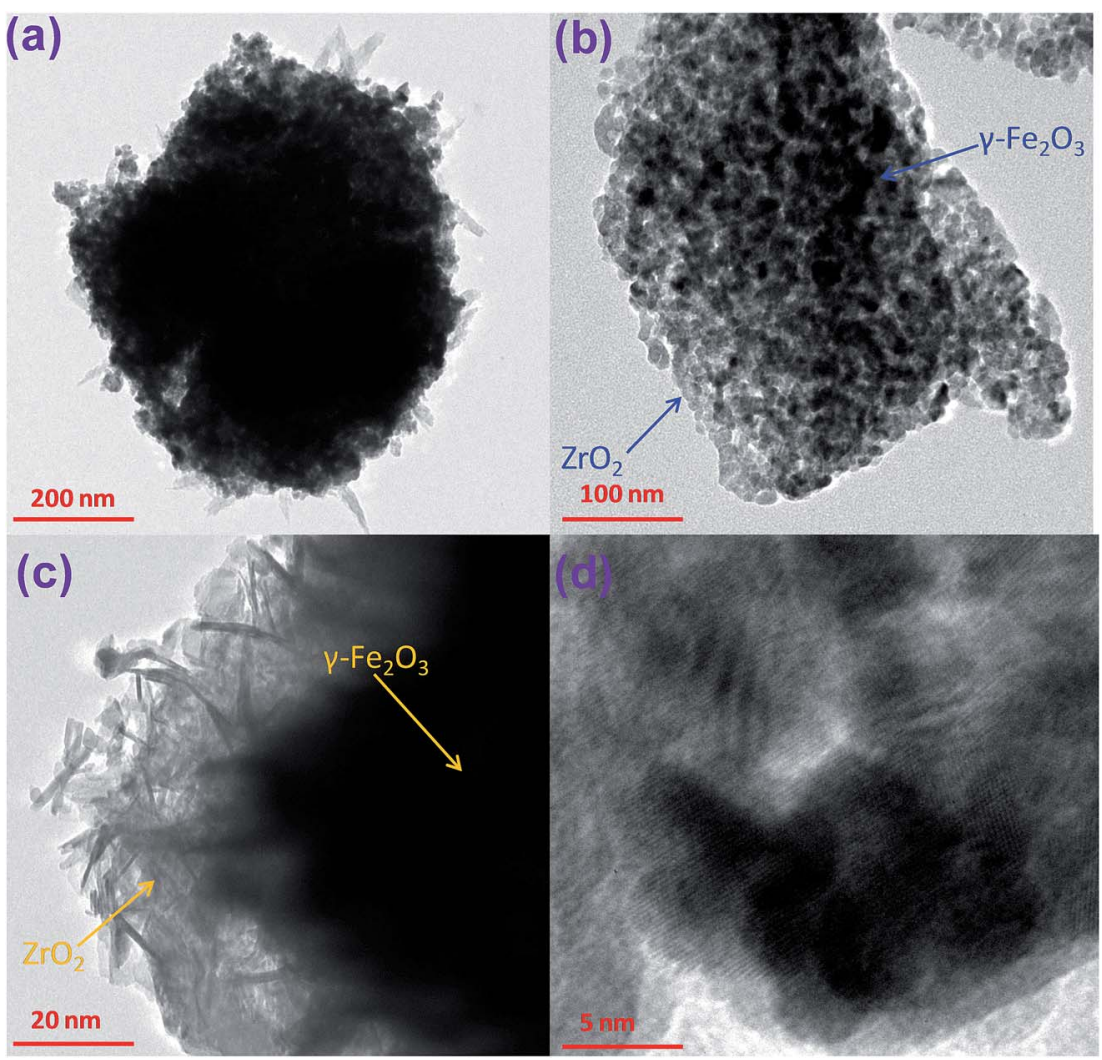

Fig. 6 TEM images of the nano-magnetic catalyst $\mathrm{K} / \mathrm{ZrO}_{2} / \gamma-\mathrm{Fe}_{2} \mathrm{O}_{3}$ at different scale.

environment, which led to the increase of the saturation magnetization. This result revealed that the coated layers significantly affected the magnetic properties of the catalysts. In comparison, the saturation magnetization of the magnetic catalyst calcined at $700{ }^{\circ} \mathrm{C}$ was only $11.03 \mathrm{emu} \mathrm{g}^{-1}$, indicating that the $\gamma-\mathrm{Fe}_{2} \mathrm{O}_{3}$, coated by $\mathrm{ZrO}_{2}$ nanoparticles, was converted to $\alpha-\mathrm{Fe}_{2} \mathrm{O}_{3}$ completely. ${ }^{29}$

\subsection{Optimization of transesterification catalyzed by magnetic catalyst}

Fig. 10a indicates that the reaction rate was slow at low temperatures and the biodiesel yield was only $67.8 \mathrm{wt} \%$ at $50{ }^{\circ} \mathrm{C}$ after $3 \mathrm{~h}$ of reaction. The biodiesel yield increased with the increase of reaction temperature to nearly $90.4 \mathrm{wt} \%$ at $65^{\circ} \mathrm{C}$, but at higher temperatures $\left(T>65^{\circ} \mathrm{C}\right)$, the methanol was vaporized and formed a large number of bubbles in the interface, which inhibited the increase of biodiesel yield, then the yield of biodiesel decreased significantly. Thus, the optimum reaction temperature was $65{ }^{\circ} \mathrm{C}$. As presented in Fig. 10b, the biodiesel yield increased from $48.5 \mathrm{wt} \%$ to $92.5 \mathrm{wt} \%$ as the molar ratio increased from $4: 1$ to $10: 1$ through $3 \mathrm{~h}$ of reaction. However, beyond the molar ratio of $10: 1$, the excessively added methanol had no significant effect on the production yield. When the amount of methanol was over $12: 1$, glycerol separation became

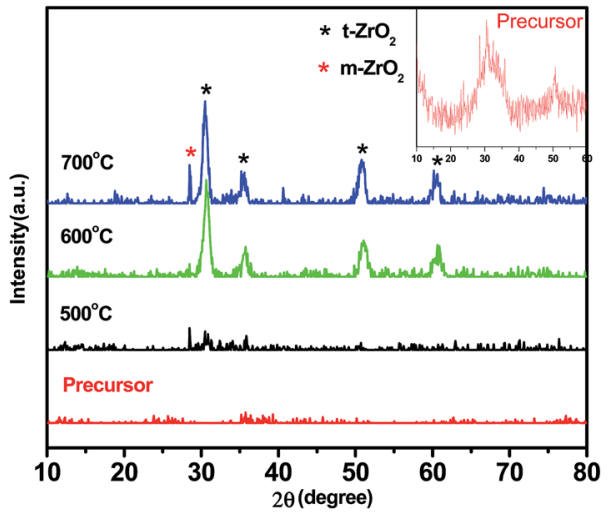

Fig. 7 XRD patterns of the magnetic precursor after calcining at different temperature.

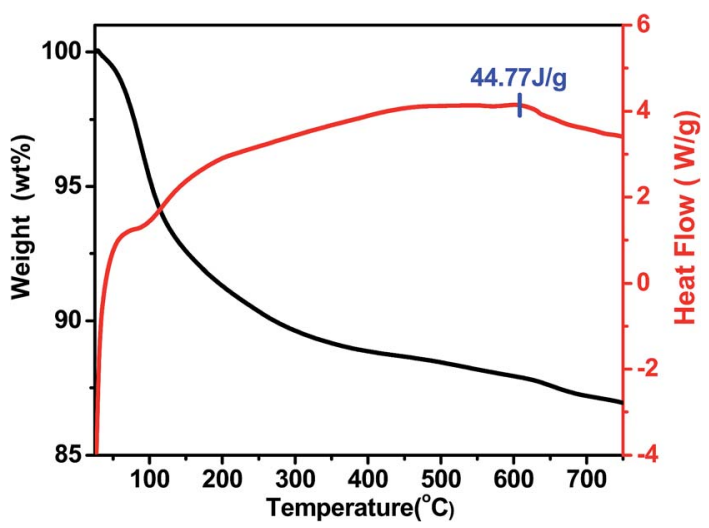

Fig. 8 The TG-DSC of the precursor. 


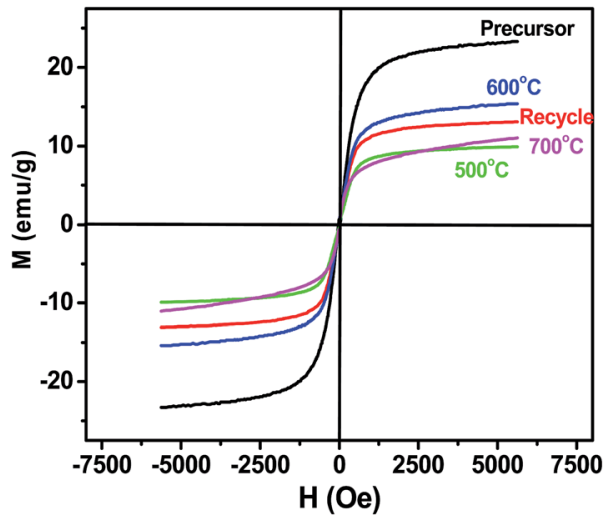

Fig. 9 Hysteresis curve of nano-magnetic catalyst.

more difficult, thus decreasing the biodiesel yield. Based on this, the optimum molar ratio of methanol to oil was $10: 1$. The mass ratio of magnetic catalyst to soybean oil was varied within the range of 2-6 wt\% (Fig. 10c). The biodiesel yield was increased with increasing catalyst and the maximum biodiesel yield was obtained by adding $5.0 \mathrm{wt} \%$ magnetic catalyst, which reached $93.6 \mathrm{wt} \%$ at $3 \mathrm{~h}$. The results indicated that with more catalyst addition, there was a faster rate at which reaction equilibrium was reached because of the increase in the total number of available active catalytic sites for the reaction. However, with further increase the catalyst amount, the biodiesel yield decreased, which was possibly due to the saponification. And only $77 \mathrm{wt} \%$ yield was obtained when the mass ratio was $6.0 \mathrm{wt} \%$. Therefore, the optimum catalyst amount was proved to be $5.0 \mathrm{wt} \%$. Fig. $10 \mathrm{~d}$ reveals that the transesterification reaction was strongly dependent on reaction time. At the beginning $(<1.5 \mathrm{~h})$, the reaction was slow due to the mixing and the dispersion of methanol into oil, and the biodiesel yield was increased in the reaction time range between $1.5 \mathrm{~h}$ and $3.5 \mathrm{~h}$. Moreover, excess reaction time led to a bit reduction in the product yield due to the backward reaction transesterification, resulting in a loss of esters as well as causing more fatty acids to form soaps. Thus, the optimum reaction time was $3.0 \mathrm{~h}$. In summary, the optimum conditions for transesterification were shown as follows: catalyst/oil molar ratio of $5 \mathrm{wt} \%$; methanol/oil molar ratio of $10: 1$; reaction time of $3.0 \mathrm{~h}$, and reaction temperature of $65{ }^{\circ} \mathrm{C}$, and the yield of biodiesel could reach above $93.6 \mathrm{wt} \%$. Compared with other magnetic catalysts $\left(\mathrm{CaFe}_{2} \mathrm{O}_{4}-\mathrm{Ca}_{2} \mathrm{Fe}_{2} \mathrm{O}_{5} 85.4\right.$ wt\% (ref. 24) and $\mathrm{CaO} / \mathrm{CoFe}_{2} \mathrm{O}_{4} 87.4$ wt\% (ref. 30)), the synthesized magnetic catalysts $\mathrm{K} / \mathrm{ZrO}_{2} / \gamma-\mathrm{Fe}_{2} \mathrm{O}_{3}$ exhibited obvious advantages in the production of biodiesel.

\subsection{Reusability of magnetic catalyst}

The reusability of the magnetic catalyst is shown in Fig. 11. After reusing six times at $65{ }^{\circ} \mathrm{C}$, the yield of biodiesel was about $74.1 \mathrm{wt} \%$ (Fig. 11a). Accordingly, the recovery rate of the catalyst also showed an obvious downward trend. This indicated that the catalyst was inevitably lost in the use and recovery process of the magnetic catalyst. Fig. 11b shows that the $\mathrm{Zr}, \mathrm{Fe}$ and $\mathrm{Zr}$ elements from the $\mathrm{K} / \mathrm{ZrO}_{2} / \gamma-\mathrm{Fe}_{2} \mathrm{O}_{3}$ catalyst were detected in the prepared biodiesel. The cumulative content showed an upward trend with the increase of the used number of the catalyst. Combined with the SEM analysis of Fig. 11c and d, it was found
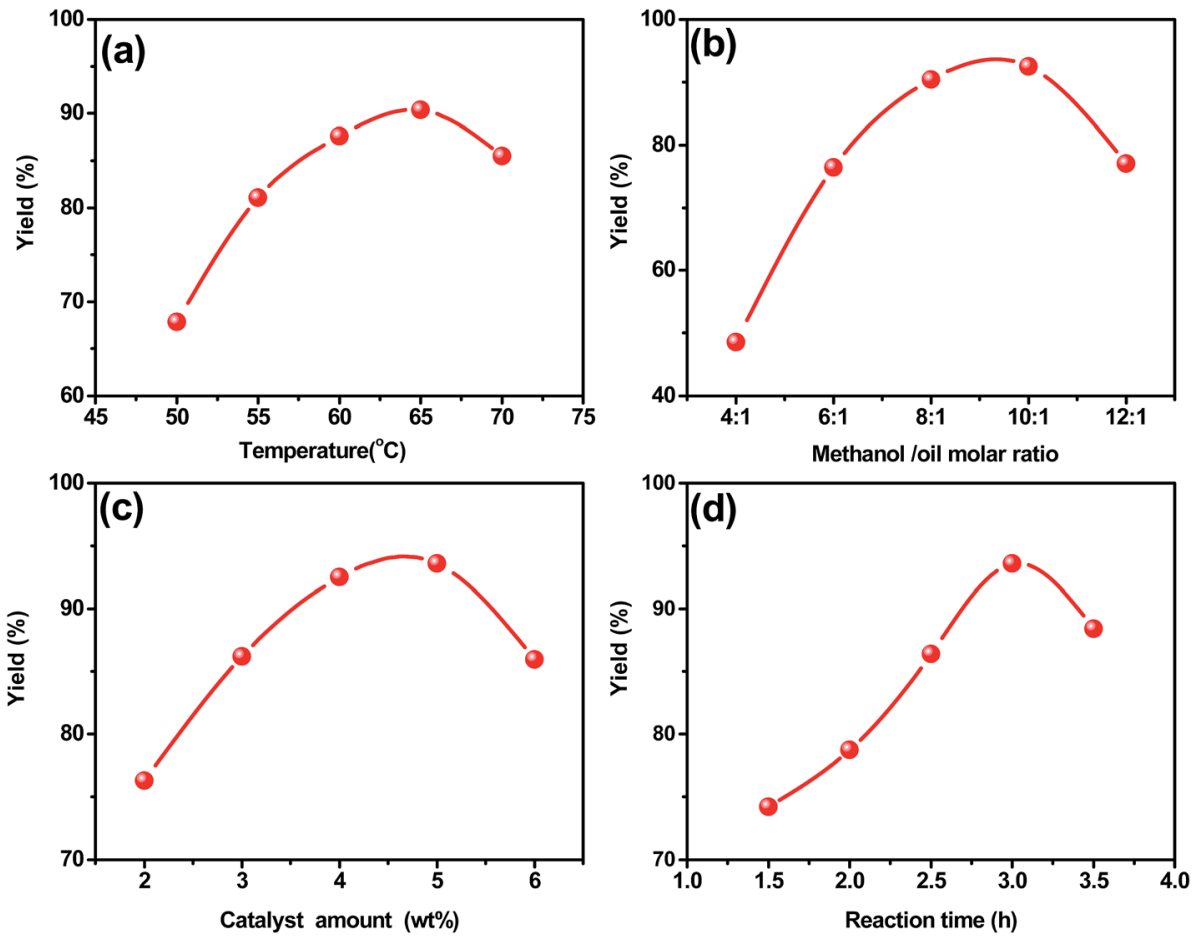

Fig. 10 Effects of (a) reaction temperature (b) methanol/oil (c) catalyst amount (d) reaction time on biodiesel yield. 

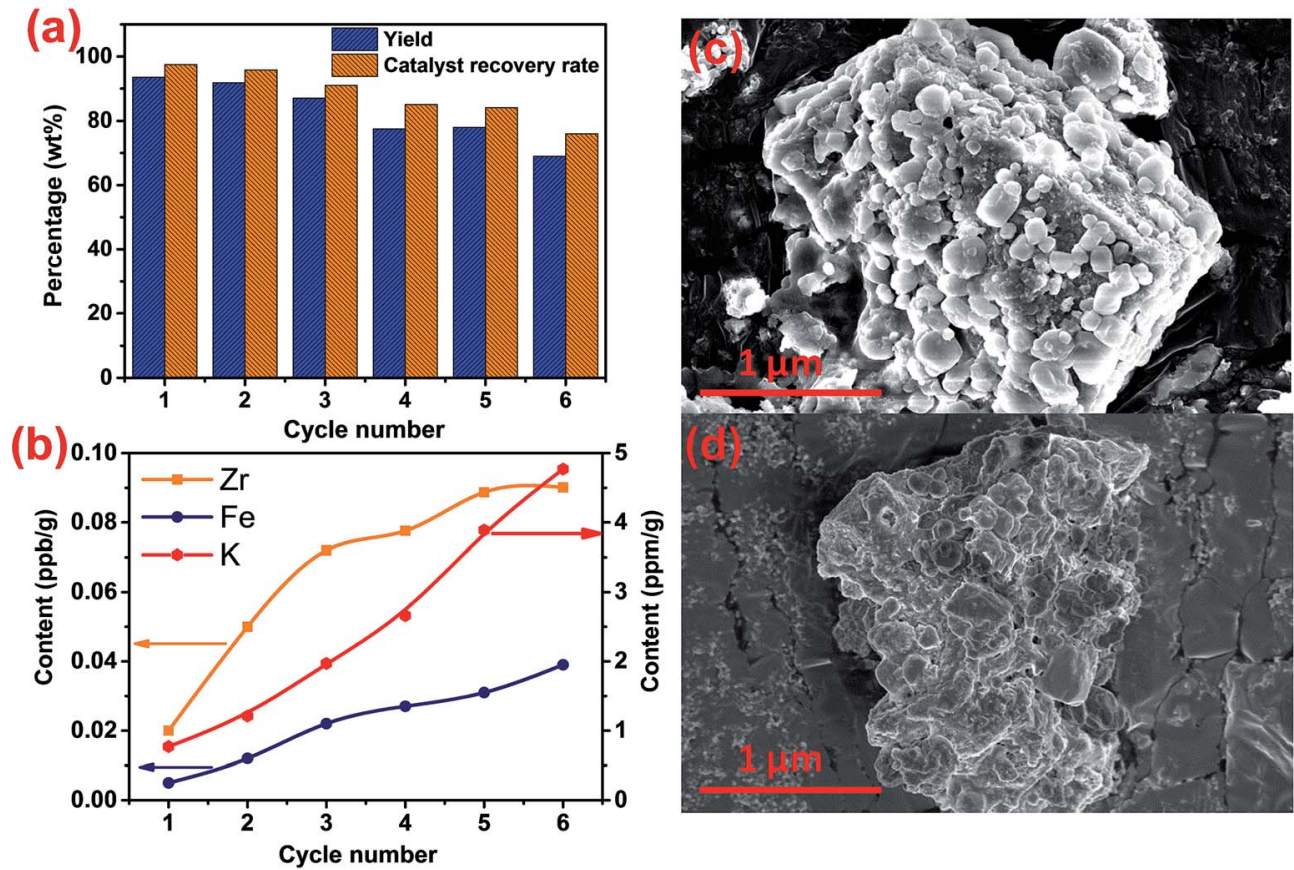

Fig. 11 (a) Reusability of the magnetic catalyst $\mathrm{K} / \mathrm{ZrO}_{2} / \gamma-\mathrm{Fe}_{2} \mathrm{O}_{3}$ (b) accumulation of the $\mathrm{Zr}$, $\mathrm{Fe}$ and $\mathrm{K}$ elements in the prepared biodiesel (c) SEM result of the initial catalyst $\mathrm{K} / \mathrm{ZrO}_{2} / \gamma-\mathrm{Fe}_{2} \mathrm{O}_{3}$ (d) $\mathrm{SEM}$ result of the catalyst $\mathrm{K} / \mathrm{ZrO}_{2} / \gamma-\mathrm{Fe}_{2} \mathrm{O}_{3}$ after six times of use (transesterification conditions: reaction temperature: $65^{\circ} \mathrm{C}$; methanol/oil: 10 : 1; catalyst amount: $5 \mathrm{wt} \%$; reaction time: $3 \mathrm{~h}$ ).

that the zirconia particles fell off from the surface of the magnetic catalyst after six times of use. Besides, the surface of the magnetic catalyst presented obvious sintering phenomenon due to multiple calcination. Therefore, the decline of yield could be considered as the loss of nano-power and alkaline sites in the process of recycling process of the $\mathrm{K} / \mathrm{ZrO}_{2} / \gamma-\mathrm{Fe}_{2} \mathrm{O}_{3}$ catalyst.

\section{Conclusion}

A nano-magnetic solid base catalyst $\mathrm{K} / \mathrm{ZrO}_{2} / \gamma-\mathrm{Fe}_{2} \mathrm{O}_{3}$ was developed by sol-gel method and characterized by various techniques. The results indicated that the nano-magnetic catalyst had a unique coated structure with an average particle diameter of $20 \mathrm{~nm}$ and a ferromagnetic property. Based on the experiments, the optimum conditions for transesterification were shown as follows: catalyst/oil molar ratio of $5 \mathrm{wt} \%$; methanol/oil molar ratio of $10: 1$; reaction time of $3.0 \mathrm{~h}$, and reaction temperature of $65{ }^{\circ} \mathrm{C}$, and the yield of biodiesel could reach above $93.6 \mathrm{wt} \%$. The nano-magnetic catalyst, $\mathrm{K} / \mathrm{ZrO}_{2} / \gamma-\mathrm{Fe}_{2} \mathrm{O}_{3}$, used in the preparation of biodiesel illustrates a good prospect of development and appears to be a promising candidate in substitution for conventional catalysts due to the high activity and their unique magnetic properties.

\section{Conflicts of interest}

There are no conflicts to declare.

\section{Acknowledgements}

Financial support from the Scientific Innovation Program of Shenzhen City, China, under basic research program (JCYJ20150626095215791), is gratefully acknowledged.

\section{References}

1 Y. Wang, S. De and N. Yan, Chem. Commun., 2016, 52, 62106224.

2 W. Li, Y. Gao, S. Yao, D. Ma and N. Yan, Green Chem., 2015, 17, 4198-4205.

3 S. K. Hoekman, A. Broch, C. Robbins, E. Ceniceros and M. Natarajan, Renewable Sustainable Energy Rev., 2012, 16, 143-169.

4 J. Xue, T. E. Grift and A. C. Hansen, Renewable Sustainable Energy Rev., 2011, 15, 1098-1116.

5 J. Yang, M. Xu, X. Zhang, Q. Hu, M. Sommerfeld and Y. Chen, Bioresour. Technol., 2011, 102, 159-165.

6 A. E. Atabani, A. S. Silitonga, I. A. Badruddin, T. Mahlia, H. Masjuki and S. Mekhilef, Renewable Sustainable Energy Rev., 2012, 16, 2070-2093.

7 R. Halim, B. Gladman, M. K. Danquah and P. A. Webley, Bioresour. Technol., 2011, 102, 178-185.

8 T. Issariyakul and A. K. Dalai, Renewable Sustainable Energy Rev., 2014, 31, 446-471.

9 R. Halim, M. K. Danquah and P. A. Webley, Biotechnol. Adv., 2012, 30, 709-732.

10 P. K. Campbell, T. Beer and D. Batten, Bioresour. Technol., 2011, 102, 50-56. 
11 I. Rawat, R. R. Kumar, T. Mutanda and F. Bux, Appl. Energy, 2013, 103, 444-467.

12 Y. Li, Y.-F. Chen, P. Chen, M. Min, W. Zhou, B. Martinez, J. Zhu and R. Ruan, Bioresour. Technol., 2011, 102, 51385144.

13 N. Yusuf, S. K. Kamarudin and Z. Yaakub, Energy Convers. Manage., 2011, 52, 2741-2751.

14 O. Özener, L. Yüksek, A. T. Ergenç and M. Özkan, Fuel, 2014, 115, 875-883.

15 L. P. Christopher, H. Kumar and V. P. Zambare, Appl. Energy, 2014, 119, 497-520.

16 E. Aransiola, T. Ojumu, O. Oyekola, T. Madzimbamuto and D. Ikhu-Omoregbe, Biomass Bioenergy, 2014, 61, 276-297.

17 A. M. Ashraful, H. Masjuki, M. Kalam, I. R. Fattah, S. Imtenan, S. Shahir and H. Mobarak, Energy Convers. Manage., 2014, 80, 202-228.

18 B. Liu and Z. Zhang, ACS Catal., 2015, 6, 326-338.

19 M. Feyzi and L. Norouzi, Renewable Energy, 2016, 94, 579586.
20 Y. Liu, P. Zhang, M. Fan and P. Jiang, Fuel, 2016, 164, 314321.

21 T. A. Ngu and Z. Li, Green Chem., 2014, 16, 1202-1210.

22 K.-L. Chang, Y.-C. Lin, S.-R. Jhang, W. L. Cheng, S.-C. Chen and S.-Y. Mao, Catalysts, 2017, 7, 203.

23 F. Zhang, Z. Fang and Y.-T. Wang, Fuel, 2015, 150, 370-377. 24 B.-j. Xue, J. Luo, F. Zhang and Z. Fang, Energy, 2014, 68, 584591.

25 S.-F. Yin, B.-Q. Xu, S.-J. Wang and C.-T. Au, Appl. Catal., A, 2006, 301, 202-210.

26 K.-T. Li, C.-K. Wang, I. Wang and C.-M. Wang, Appl. Catal., A, 2011, 392, 180-183.

27 M. Kim, C. DiMaggio, S. Yan, H. Wang, S. O. Salley and K. S. Ng, Bioresour. Technol., 2011, 102, 2380-2386.

28 M. M. Can, M. Coşkun and T. Firat, J. Alloys Compd., 2012, 542, 241-247.

29 M. M. Can, M. Coşkun and T. Fırat, J. Alloys Compd., 2012, 542, 241-247.

30 P. Zhang, Q. Han, M. Fan and P. Jiang, Appl. Surf. Sci., 2014, 317, 1125-1130. 